\title{
ОЦІНКА СТАБІЛЬНОСТІ ТРІОННИХ СТАНІВ У ВУГЛЕЦЕВИХ НАНОТРУБКАХ ТИПУ ЗИГЗАГ
}

\author{
C. MАРЧEHKO ${ }^{1,2}$ \\ ${ }^{1}$ Кафедра теоретичної фізики, \\ Одеський національний університет ім. I.I. Мечникова \\ (2, Вул. Дворянсъка, Одеса 65026; e-mail: Sergey. Marchenko@ оnu. edu. ua)
}

УДК 538.9; 538.958

${ }^{2}$ Кафедра біофизики, інформатики та медичного обладнання,

Одеський національний медичний університет

(2, Валіховсъкий провул., Одеса 65026)

де себе як позитивно заряджена частинка. Так, електрон і дірка, взаємодіючи виключно за допомогою кулонівської взаємодії, можуть утворювати зв'язані стани. Такі стани називаються екситонами. У цілому розрізняють два типи екситонів: екситони Френкеля і екситони Ван'є-Мотта.

Вуглецеві нанотрубки належать до класу прямозонних напівпровідників. Тому в них може відбуватися анігіляція електрон-діркових пар з випусканням фотона [5]. Екситони, локалізовані у вуглецевих нанотрубках, мають додаткову зв'язність - діаметр нанотрубки є фіксованим, тому такі екситони можна розглядати як суто одновимірні об'єкти.

Як відомо, у квазіодновимірних системах значно посилюється кулонівська взаємодія. Це приводить до зростання стабільності екситоноподібних збуджень, що значно посилює існуючу кулонівську блокаду. Разом із сильними поляризаційними ефектами це приводить до того, що нові екситони майже не утворюються. Тобто, декілька екситонів, що утворилися у нанотрубці, мають блокувати утворення нових, тому їх концентрація має бути мізерною. Питання щодо впливу екранування екситонами на утворення нових багаточастинкових збуджень описано в роботі $[6]$.

Утворення екситонів у вуглецевих нанотрубках можливе, якщо енергія, що породжує електрон-діркову пару, дорівнює або менша за ширину забороненої зони. У випадку, коли енергії достатньо, щоб електрон потрапив у зону провідності, а дірка, відповідно, у валентну зону, то тоді утворюється пара електрон і дірка, які не взаємодіють між собою і є самостійними частинками.

У одновимірних нанотрубках реалізовуються екситони з радіусом набагато більшим сталої гратки, що є аналогічними екситонам Ван'є-Мотта у тривимірних кристалах. Масою екситона буде зведена маси еле- 
ктрона і дірки:

$\mu=\frac{m_{e} m_{h}}{m_{e}+m_{h}}$,

де $m_{e}$ і $m_{e}$ - ефективні маси електрона та дірки. Значення ефективних мас залежать від кристалічної структури нанотрубки. Послідовно їх можна розрахувати, використовуючи вирази з роботи [11]. Взаємодію між електроном і діркою будемо вважати суто кулонівською.

Виникає, однак, питання, що вважати діелектричною проникністю. Для вуглецевих нанотрубок екрануючий вплив її зарядів проявляється лише на відстанях порядку діаметра трубки. Тому в першому наближенні можна вважати, що для нанотрубок $\varepsilon=1$. Зазначимо, що якщо нанотрубка знаходиться у середовищі (наприклад, у міцелах), то за значення діелектричної проникності має бути прийняте значення, відповідне цьому середовищу, що змінить енергії екситонних збуджень.

Для оцінки значень енергій екситоноподібних збуджень в даній роботі використовували добре відомий метод Рітца [7]. Нагадаємо, що за допомогою цього методу можна отримати оцінку зверху на власні значення енергії. Зазначимо, що нас цікавлять питання стабільності екситонних збуджень відносно одноелектронних станів та стабільності тріонних станів відносно розпаду на екситон та дірку (електрон). Тому при розрахунках у межах однієї моделі навіть такий грубий метод дасть якісно вірні результати.

Для оцінки власних значень енергї використаємо рівняння Шредінгера вигляду

$\left[-\frac{\hbar^{2}}{2 \mu} \frac{\partial^{2}}{\partial x^{2}}-\frac{e^{2}}{\sqrt{x^{2}+d^{2}}}\right] \Psi=E \Psi$.

Тут $\mu$ - зведена маса екситона, $e$ - елементарний заряд, $x$ - відстань між електроном і діркою вздовж нанотрубки, $d$ - параметр, який залежить від діаметра нанотрубки, що в першому наближенні дорівнює самому діаметру. Звернемо увагу на те, що потенціал у цьому рівнянні є парною функцією. Тому екситонні стани у трубках розпадаються на дві серії: парну, якій відповідають парні хвильові функції, і непарну, для якої власні функції непарні. Спектр екситонів непарної серії подібний до спектрів інших водневоподібних систем. При цьому дозволені оптичні переходи будуть між станами, відповідними парній та непарній серіям. Враховуючи те, що для станів непарної серії хвильові функції обертаються на нуль при $x=0$, власні значення енергії для цих станів можуть бути знайдені як власні значення крайової задачі для рівняння (2) на півосі $(0,+\infty)$ з крайовою умовою

$\Psi(0)=0$.

Аналогічно, спектр парної серії визначається крайовою умовою

$\Psi^{\prime}(0)=0$.

Гамільтоніан, що входить у (2), можна застосовувати у випадку, коли діелектрична проникність середовища, в якому знаходиться трубка, близька до одиниці. Використання в моделі обрізаного кулонівського потенціалу зумовлене одновимірністю задачі задля прибирання сингулярності у нулі (якої не повинно бути з фізичних міркувань). Якщо ж переходити до послідовного розгляду трубки як циліндра, то на основі цього потенціалу будується більш точний потенціал у вигляді еліптичного інтеграла, що було зроблено, наприклад, у роботі [8].

$\mathrm{У}$ використаному методі єдиним критерієм вибору пробних функцій є лише їх відповідність крайовим умовам. Ми також будемо вимагати від них інтегрованості та гладкості, що не є строгою вимогою, а лише має спростити розрахунки. Поведінка вибраних хвильових функцій екситонів цілком збігається з поведінкою точних функцій заданих графічно, що описані в огляді М. Дресельхаус [9].

Ми використовували пробні функції такого вигляду:

$\Psi_{\text {even }}(x)=C_{1} \exp \left[-\alpha x^{2}\right]$

для парної серії та

$\Psi_{\text {odd }}(x)=C_{2} x \exp \left[-\alpha x^{2}\right]$

для непарної.

Треба позбавитися від розмірних коефіцієнтів, тому перейдемо до атомних одиниць. Приймаємо, що $\mu=1, \hbar=1$ та $e=1$. Одиницею довжини буде борівський радіус екситона. Зрозуміло, що він залежатиме від ефективної маси екситона і діаметра трубки. Таким чином, в остаточному рівнянні діаметр трубки потрібно переписати у введених атомних одиницях.

У такому випадку основний стан парної серії наближено збігається з мінімумом функції

$I_{1}(\alpha)=\frac{\hbar^{2} \sqrt{2 \pi \alpha}}{8 \mu}-\frac{1}{2} e^{2} e^{\alpha d^{2}} K_{0}\left[\alpha d^{2}\right]$,

а для непарної серії - 3 мінімумом функції

$I_{2}(\alpha)=\frac{\hbar^{2} \sqrt{2 \pi \alpha}}{14 \alpha \mu}+\frac{1}{8} \frac{e^{2} \sqrt{\pi}}{\alpha} U\left[\frac{1}{2}, 0,2 \alpha d^{2}\right]$. 


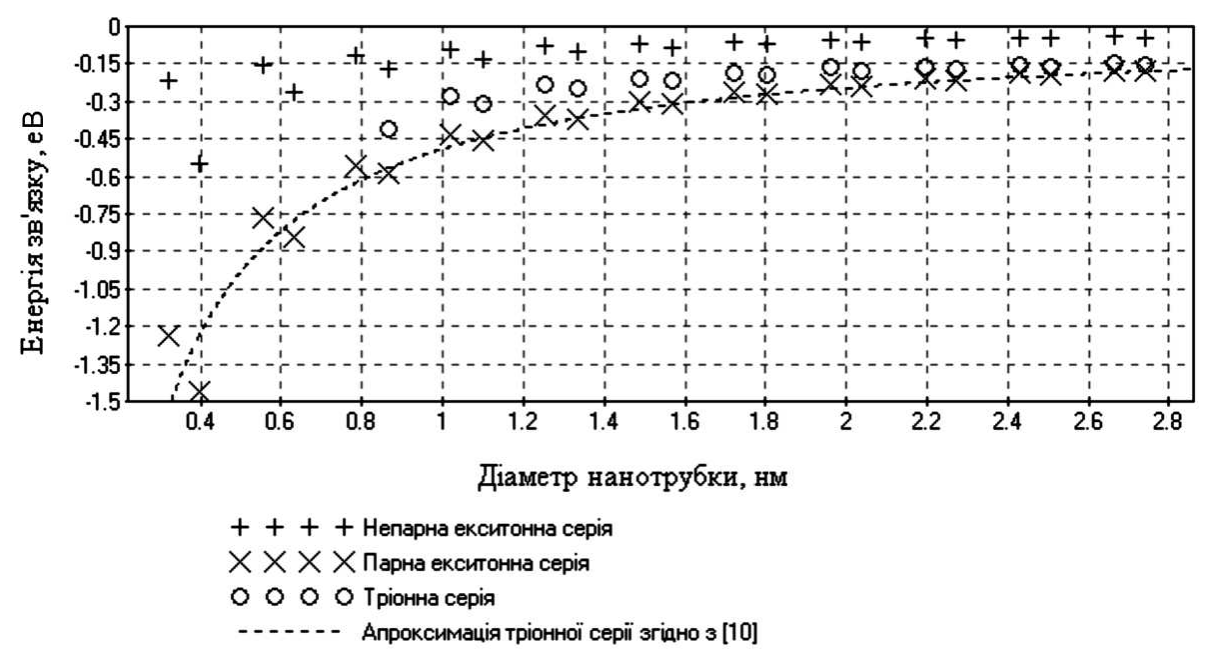

Рис. 1. Залежність енергій зв'язку тріонів та екситонів обох серій від діаметра нанотрубки локалізації та порівняння з апроксимаційним виразом

Тут $K_{n}[x]-$ модифікована функція Бесселя другого роду, а $U[a, b, z]$ - вироджена гіпергеометрична функція.

Зазначимо, що при використанні варіаційного методу Рітца отримуємо чисельний ряд (у нашому випадку отримали його у вигляді функцій (7), (8)), кожен член якого більший або дорівнює точному розв'язку. Таким чином, найменший з членів ряду (в нашому випадку екстремум відповідної функції) буде найближчим до точного розв'язку і наближатиметься саме зверху.

Вибір функцій є досить грубим, але така грубість у виборі пробних функцій може лише підвищити енергії основних станів і якщо енергія зв'язку екситона, яка була отримана у межах варіаційного методу, виявиться більшою за ширину забороненої зони в нанотрубці, то вона буде більшою за ширину забороненої зони і для точного розв'язку.

Мінімуми функцій лежать у негативній області, причому перший мінімум нижче другого. Той факт, що енергії основних станів лежать у негативній області означає, що стан є зв'язаним (тобто, в данному випадку, він існує).

На рис. 1 наведено залежність енергій екситонів обох серій від діаметра нанотрубки локалізації. Можна зауважити, що істотне розходження в енергії зв'язку екситонів для нанотрубок малих діаметрів при збільшенні такого дедалі більше нівелюється, тобто для трубок великого діаметра відмінності екситонних спектрів менш істотні, ніж для тонких.

\section{3. Тріонні стани}

Тріон являє собою зв'язаний стан, що складається 3 двох електронів та дірки або з двох дірок і електрона. Фактично це іонізований стан екситонної молекули (біекситона). Також, часто можна зустріти назву "заряджений екситон” (charged exciton). Вперше експериментальне спостереження тріонного стану у вуглецевих нанотрубках було описано в роботі [10], до результатів якої ми звернемося далі.

Для знаходження власних значень енергій зв'язку тріонів, як і у випадку з екситонами, будемо розв'язувати відповідне рівняння Шредінгера. Для спрощення моделі допустимо не враховувати відмінність ефективних мас електронів і дірок (насправді їх маси відрізняються менше ніж на 3 відсотки [11]). Таким чином, маса тріона дорівнюватиме просто ефективній масі дірки. Також, вважаючи, що взаємодія між кожною парою частинок, що складають тріон, є суто кулонівською, можна записати гамільтоніан для одновимірного тріона в нанотрубці як:

$$
\begin{aligned}
& \hat{H}=-\frac{\hbar^{2}}{2 m_{h}}\left[\frac{\partial^{2}}{\partial x^{2}}+\frac{\partial^{2}}{\partial \xi_{1}^{2}}+\frac{\partial^{2}}{\partial \xi_{2}^{2}}\right]-\frac{e^{2}}{\sqrt{\left(x-\xi_{1}\right)^{2}+d^{2}}}- \\
& -\frac{e^{2}}{\sqrt{\left(x-\xi_{2}\right)^{2}+d^{2}}}+\frac{e^{2}}{\sqrt{\left(\xi_{1}-\xi_{2}\right)^{2}+d^{2}}}
\end{aligned}
$$

де $x, \xi_{1}, \xi_{2}$ - координати електрона і двох дірок відповідно; $e$ - заряд електрона; $d$ - параметр, що залежить від діаметра нанотрубки, який, як і у випадку екситонів, може дорівнювати самому значенню діаметра; 
$m_{h}$ - маса тріона, що в даному випадку збігається 3 масою дірки;

Тріон, фактично, являє собою три зв'язаних двочасткових стани - двох екситонних і одного дірководіркового. Таким чином, цілком природним буде побудова хвильової функції тріона у вигляді добутку хвильових функцій, що відповідають цим станам. Тобто хвильову функцію вибирали як комбінацію трьох гауссових експонент, які відповідають трьом складовим двочастковим станам, та плоскої хвилі, яка описує рух центра мас системи як цілого, тобто

$\Psi_{X^{ \pm}}=C_{3}\left(\xi_{1}-\xi_{2}\right) \exp \left[-\alpha\left\{\left(x-\xi_{1}\right)^{2}+\left(x-\xi_{2}\right)^{2}\right\}\right] \times$

$\times \exp \left[-\beta\left(\xi_{1}-\xi_{2}\right)^{2}\right] \exp \left[-i p\left(x+\xi_{1}+\xi_{2}\right)\right]$,

де $\alpha$ і $\beta$ - малі параметри.

Наявність різниці координат дірок, що входить як множник у хвильову функцію, вказує на те, що при зближенні дірок, що входять до складу тріона, імовірність реалізації такого стану буде зменшуватися і прямувати до нуля при нескінченно близькому розташуванні дірок.

Мінімізуючу функцію не приводимо тут через іï складний вираз, що не несе фізичної інформації. Мiнімуми функцій знаходили чисельно.

Нанотрубки модифікації зигзаг з діаметром менше нанометра не розглядалися, оскільки: такі тонкі нанотрубки не спостерігаються як самостійні об'єкти, а тільки лише як один із шарів багатошарової трубки.

Як було зазначено раніше, вперше експеримент, в якому спостерігалися лінії, що могли би ідентифікуватися як тріонні, було зроблено лише на початку 2011 року та описано в [10]. У серї̈ експериментів по спостереженню тріонних ліній було встановлено наближену залежність енергї тріонного збудження залежно від діаметра трубки як $E_{X \pm} \approx \frac{40}{d}$ для середовища 3 діелектричною проникністю $\varepsilon_{\mathrm{env}}=3,5$. Для порівняння з нашими результатами можливо використати вираз, що приводить до "вакуумних" енергій:

$E_{X^{ \pm}} \approx \frac{40}{d} \varepsilon_{\mathrm{env}}^{2}$

Цю залежність наведено на рис. 1. Як і пророкує теорія, оціночні значення, отримані варіаційним методом, наближаються до тих, що випливають з експерименту саме зверху.

Цікавий той факт, що значення енергії зв'язку тріонів для всіх розглянутих зразків виявлялося більш високоенергетичним по відношенню до значень відповідних енергій екситонів парної серії, але при цьому менше енергій зв'язку екситонних збуджень непарної серії (таблиця). Нагадаємо, що екситони непарної серії є першим збудженим станом, а парної - основним. Таким чином, тріон може "народитися" в результаті захоплення екситонами, що знаходяться у збудженому стані вільного електрона із зони провідності або дірки з валентної зони, що знизить сумарну енергію системи. Такий тріон буде так званою ексимерною сполукою, оскільки в його утворенні бере участь збуджений екситон.

Ексимерні сполуки, енергї зв'язку яких перевищують енергію основного стану, не можуть існувати нескінченно довго. Вони мають розпадатися протягом досить невеликого часу, за допомогою оптичного або безвипромінювального переходу.

Наголосимо, що оскільки тріон може "народитися" тільки при захопленні дірки або електрона збудженим екситоном (з пониженням енергії), а той, у свою чергу, може утворитися з незбудженого екситону при поглинанні останнім енергії, то ми маємо люмінесцен-

Т а б л и ц я. Енергії частинок екситонної родини для різних нанотрубок типу зигзаг порівняно 3 шириною забороненої зони. Значення заборонених зон взято з [11]. Тут $(n, m)$ - індекси хіральності нанотрубки, $d-$ діаметр нанотрубки, $E\left(X_{\text {even }}\right)$ - енергія екситонів парної серії, $E\left(X^{ \pm}\right)$- енергії тріонів, $E\left(X_{\text {odd }}\right)$ - енергія екситонів непарної серії , $E_{\text {gap }}$ - ширина забороненої зони

\begin{tabular}{ccc|c|c|c|c}
\hline$(n, m)$ & $d, \mathrm{HM}$ & $E\left(X_{\text {odd }}\right), \mathrm{eB}$ & $E\left(X^{ \pm}\right), \mathrm{eB}$ & $E\left(X_{\text {even }}\right), \mathrm{eB}$ & $E_{\text {gap }}, \mathrm{eB}$ \\
\hline$(4,0)$ & 0,3214 & $-1,2434$ & - & $-0,2154$ & 2,0749 \\
$(5,0)$ & 0,3980 & $-1,4602$ & - & $-0,5511$ & 2,3423 \\
$(7,0)$ & 0,5526 & $-0,7691$ & - & $-0,1530$ & 1,3416 \\
$(8,0)$ & 0,6304 & $-0,8392$ & - & $-0,2612$ & 1,4153 \\
$(10,0)$ & 0,7861 & $-0,5561$ & - & $-0,1172$ & 0,9774 \\
$(11,0)$ & 0,8641 & $-0,5911$ & $-0,3293$ & $-0,1720$ & 1,0115 \\
$(13,0)$ & 1,0202 & $-0,4363$ & $-0,2288$ & $-0,0948$ & 0,7667 \\
$(14,0)$ & 1,0983 & $-0,4563$ & $-0,2188$ & $-0,1280$ & 0,7865 \\
$(16,0)$ & 1,2546 & $-0,3583$ & $-0,1652$ & $-0,0796$ & 0,6302 \\
$(17,0)$ & 1,3328 & $-0,3721$ & $-0,1581$ & $-0,1020$ & 0,6431 \\
$(19,0)$ & 1,4892 & $-0,3042$ & $-0,1328$ & $-0,0679$ & 0,5348 \\
$(20,0)$ & 1,5674 & $-0,3132$ & $-0,1268$ & $-0,0842$ & 0,5439 \\
$(22,0)$ & 1,7238 & $-0,2644$ & $-0,1019$ & $-0,0601$ & 0,4643 \\
$(23,0)$ & 1,8020 & $-0,2712$ & $-0,0968$ & $-0,0720$ & 0,4711 \\
$(25,0)$ & 1,9585 & $-0,2333$ & $-0,0769$ & $-0,0535$ & 0,4103 \\
$(26,0)$ & 2,0367 & $-0,2391$ & $-0,0739$ & $-0,0628$ & 0,4156 \\
$(28,0)$ & 2,1932 & $-0,2090$ & $-0,0700$ & $-0,0484$ & 0,3675 \\
$(29,0)$ & 2,2715 & $-0,2130$ & $-0,0676$ & $-0,0557$ & 0,3717 \\
$(31,0)$ & 2,4280 & $-0,1890$ & $-0,0633$ & $-0,0441$ & 0,3328 \\
$(32,0)$ & 2,5062 & $-0,1930$ & $-0,0624$ & $-0,0501$ & 0,3362 \\
$(34,0)$ & 2,6628 & $-0,1740$ & $-0,0576$ & $-0,0404$ & 0,3040 \\
$(35,0)$ & 2,7410 & $-0,1760$ & $-0,0567$ & $-0,0454$ & 0,3069 \\
\hline & & & & &
\end{tabular}




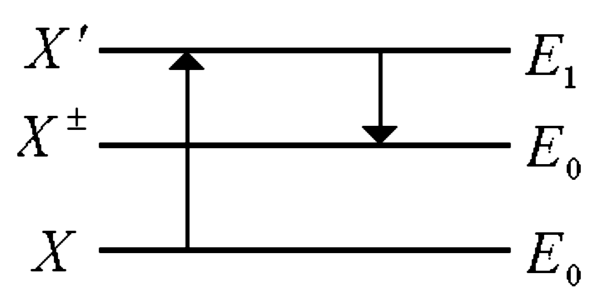

Рис. 2. Для того щоб породити тріон треба перевести екситон у збуджений стан. Це приводить до появи ліній поглинання та випромінювання, подібних до тих, що спостерігаються при люмінесценції. Тут $E_{0}(X)$ - енергія основного екситонного стану, $E_{0}\left(X^{ \pm}\right)$- енергія основного тріонного стану, $E_{1}\left(X^{\prime}\right)$ - енергія першого збудженого екситонного стану

тну трирівневу систему (рис. 2). Цей факт може бути використано як для ідентифікації нанотрубок, так і в технологічних пристроях (система з накачкою).

\section{4. Висновки}

Показано, що тріонні збудження в ОВНТ модифікацій зигзаг є ексимерами, які утворюються при захопленні вільного електрона або дірки збудженим екситоном. Збуджений екситонний стан в ОВНТ є нестійким відносно тріонного, що вкупі з нестійкістю тріона відносно основного екситонного стану приводить до появи трирівневої енергетичної системи. Це, з урахуванням малих концентрацій, вказує на принципову можливість створення ексимерного інфрачервоного випромінювача, що працює в однофотонному режимі.

1. Carbon Nanotubes: Advanced Topics in the Synthesis, edited by A. Jorio et al. (Springer, Berlin, 2008).

2. T. Ando, J. Phys. Soc. Jpn. 66, 1066 (1997).

3. F. Wang et al., Science 308, 838 (2005).

4. F. Wang et al., Phys. Rev. Lett. 99, 227401 (2007).

5. J. Chen, V. Perebeinos, M. Freitag, J. Tsang, Q. Fu, J. Liu, and Ph. Avouris, Science 310, 1171 (2005).

6. V.M. Adamyan, O.A. Smyrnov, and S.V. Tishchenko, J. Phys.: Conf. Ser. 129, 012012 (2008).

7. R. Courant and D. Hilbert, Methods of Mathematical Physics (Interscience Publishers, New York, 1953), Vol. 1, p. 175
8. O.A. Smyrnov, Ukr. J. Phys. 55, 1217 (2010).

9. M.S. Dresselhaus, G. Dresselhaus, R. Saito, and A. Jorio, Annu. Rev. Phys. Chem. 58, 719 (2007).

10. R. Matsunaga, K. Matsuda, and Y. Kanemitsu, Phys. Rev. Lett. 106, 037404 (2011).

11. S.V. Tishchenko, Low Temp. Phys. 32, 953 (2006).

Одержано 19.11.11

\section{ОЦЕНКА СТАБИЛЬНОСТИ ТРИОННЫХ СОСТОЯНИЙ} В УГЛЕРОДНЫХ НАНОТРУБКАХ ТИПА ЗИГЗАГ

C. Марченко

Р ез ю м е

Оценены стабильности трионных возбуждений в углеродных нанотрубках типа зигзаг. Показано, что трион является нестабильным относительно основного экситонного состояния и стабильным относительно возбужденного. Итак, трионы в нанотрубках этого типа могут быть образованы за счет захвата дырки или электрона экситоном, находящемся в возбужденном состоянии. Иными словами, трион в нанотрубке является эксимерным соединением, что приводит к появлению трехуровневой энергетической системы (невозбужденный экситонтрион-возбужденный экситон).

\section{STABILITY OF TRIONIC STATES IN ZIGZAG CARBON NANOTUBES}

S. Marchenko ${ }^{1,2}$

${ }^{1}$ Department of Theoretical Physics,

I.I. Mechnikov Odesa National University

(2, Dvorianska Str., Odesa 65026, Ukraine;

e-mail: Sergey.Marchenko@onu.edu.ua),

${ }^{2}$ Department of Biophysics, Informatics and Medical Equipment, Odesa National Medical University

(2, Valikhovskyi Lane, Odesa 65026, Ukraine)

$\mathrm{S} \mathrm{u} \mathrm{m} \mathrm{m} \mathrm{a} \mathrm{r} \mathrm{y}$

The stability of trionic excitations in zigzag carbon nanotubes has been estimated. A trion is shown to be unstable with respect to the ground excitonic state and stable with respect to the excited one. So, trions in nanotubes of this type can be formed by capturing an electron or a hole by an excited exciton. In other words, the trion in a nanotube is an excimer complex, which results in the formation of a system with three energy levels (unexcited excitontrion-excited exciton). 